\title{
APLICAÇÃO DO MÉTODO SERVQUAL NA AVALIAÇÃO DA SATISFAÇÃO DE CLIENTES DE UMA ACADEMIA DE GINÁSTICA
}

\section{APPLICATION OF SERVQUAL METHOD IN THE ASSESSMENT OF CUSTOMER SATISFACTION AN ACADEMY OF GYMNASTICS}

\author{
Eduardo Guimarães Lima Barreto ${ }^{1}$; Roberta de Lourdes Silva dos Santos ${ }^{2}$; Luiz Bueno da Silva ${ }^{3}$; \\ Maria de Lourdes Barreto Gomes ${ }^{4}$; Valeska Lisandra de Menezes ${ }^{5}$ \\ ${ }^{1}$ Universidade Federal da Paraíba - UFPB - João Pessoa - Brasil \\ eduardoguima@gmail.com \\ ${ }^{2}$ Universidade Federal da Paraíba - UFPB - João Pessoa - Brasil \\ robertalss@globo.com \\ ${ }^{3}$ Universidade Federal da Paraíba - UFPB - João Pessoa - Brasil \\ bueno@ct.ufpb.br \\ ${ }^{4}$ Universidade Federal da Paraíba - UFPB - João Pessoa - Brasil \\ marilu@ct.ufpb.br \\ ${ }^{5}$ Universidade Federal da Paraíba - UFPB - João Pessoa - Brasil \\ menezes_valeska@hotmail.com
}

\begin{abstract}
Resumo
O crescente número de academias de ginástica e conseqüentemente da demanda pelos serviços oferecidos neste tipo de empreendimento, e sobretudo a alta rotatividade, ou seja, a grande dificuldade apresentada na retenção de clientes levaram a investigação e aprofundamento do tema proposto. A qualidade dos serviços é de difícil mensuração e depende de diversos fatores até que atenda às expectativas dos clientes e possa ser reconhecida pelos mesmos. Nem todas as empresas têm conseguido atingir as reais necessidades de seus clientes. Na tentativa de analisar a qualidade dos serviços prestados em uma academia de ginástica realizou-se uma pesquisa com a participação de 92 clientes. Como instrumento de pesquisa utilizou-se uma adaptação da escala SERVQUAL, que compara expectativas com percepções dos clientes em relação às cinco dimensões da qualidade: tangibilidade, responsabilidade, confiabilidade, empatia e garantia. Como resultado, obteve-se um panorama geral da qualidade percebida pelos clientes, dos serviços oferecidos, mostrando os pontos fortes e fracos do sistema.
\end{abstract}

Palavras-chave: Qualidade; Serviços; Academias de Ginástica; SERVQUAL.

\section{Introdução}

Definir o posicionamento mercadológico no atual cenário se constitui uma questão de grande desafio para as empresas, independente do porte ou setor. As academias de ginástica, como quaisquer outros tipos de empresa, precisam acompanhar os processos de mudança. 
A cada dia novos equipamentos e tecnologias são inseridos nesse mercado. A ciência estuda novas possibilidades para a tão sonhada obtenção do "corpo perfeito". Os conceitos de ergonomia, qualidade de vida, marketing, saúde, bem-estar, entre outros, invadiram o universo da Educação Física. O cliente, pelo fácil acesso à informação e experiência vivida pela concorrência global, tornou-se ainda mais exigente de seus direitos.

Segundo Juran (1993), a satisfação de um cliente com um bem e/ou serviço, tem a sua origem nas características destes e esta é a razão de os adquirirem. Por outro lado, a insatisfação com produto (bens e/ou serviços) tem a sua origem nas não conformidades percebidas após a sua experimentação. Por essa razão os clientes reclamam ou desistem da continuidade de utilização do serviço.

Sobre este fato, tomando como exemplo os gestores de academias, Saba (2008) enfatiza que a própria postura contribui para a baixa aderência das pessoas a exercícios físicos, quando se preocupam apenas com a conquista de novos alunos e esquecem o principal: criar estratégias para a retenção dos alunos antigos.

Pereira (2005) ressalta que o segredo do sucesso pertence às academias que valorizam seus colaboradores, reconhecem suas obrigações perante a sociedade e têm uma atenção muito grande com o cliente e a qualidade de seus serviços.

A satisfação do cliente está intrinsecamente relacionada à cultura organizacional. Não basta captar clientes e oferecer o básico, mas estudar seu comportamento e encantá-lo, superando suas expectativas. Para tanto, uma correlação entre gestores, clientes externos e internos deverá estar alinhada a um modelo de gestão da qualidade. Cuidar da qualidade há muito tempo deixou de ser fator diferenciador e passou a ser um requisito indispensável para se participar do mercado (PEINADO, 2007).

Este artigo fez uma análise da qualidade dos serviços prestados por uma academia de ginástica através do método SERVQUAL, mensurando os níveis de expectativa e percepção dos clientes sobre os serviços propostos e prestados dentro das cinco dimensões da qualidade: tangibilidade, responsabilidade, confiabilidade, empatia e garantia dos serviços.

\section{Considerações sobre qualidade}

A qualidade tornou-se necessidade premente para o estabelecimento e crescimento empresarial, seja do produto ou serviço. Conforme Batalha (2008) é possível observar quatro eras distintas sobre a evolução da "qualidade”, desde a Revolução Industrial à atualidade:

- $1^{a}$ era: A era da inspeção. O modelo Taylorista surge traduzindo uma abordagem predominantemente corretiva. O modelo Fordista adota a intercambialidade, com um sistema de padronização de medidas, caracterizando o modelo da linha de montagem. 
- $\quad 2^{\mathrm{a}}$ era: A era do controle. Como controlar a qualidade? A era ficou marcada pela criação de controles estatísticos, monitoramento, proposta do ciclo de melhoria contínua (PDCA) enfim, começa a se desenvolver a normalização para a qualidade.

- $3^{\text {a }}$ era: A era da garantia. Para garantir a qualidade aparece a primeira abordagem sistêmica - TQC (Total Quality Control) - abrangendo a totalidade nas áreas da organização, ou seja, incluindo a relação com clientes e fornecedores no processo, antes voltada apenas ao o setor produtivo. Solução de problemas, sistemas, custos e planejamento da qualidade tornaram-se ferramentas amplamente estudadas e incorporadas ao conceito de garantia da qualidade.

- $4^{\text {a }}$ era: A era da gestão. Iniciada fortemente no Japão, evidenciando o controle da qualidade por toda a empresa - TWQC (Company Wide Quality Control). Além dos fundamentos do TQM (Qualidade Total Management) aspectos como aversão ao desperdício, melhoria contínua e participação dos colaboradores foram incorporados ao conceito.

O conceito de qualidade segundo Batalha (2008) é bastante complexo e de difícil consenso, podendo assumir diversos significados, dependendo das idiossincrasias de cada indivíduo. De alguma forma, todos parecem entender do que se trata, especificamente ao analisar se algum produto tem qualidade ou não, mas ao tentar definir, logo se conclui a dificuldade em normatizar a terminologia.

Para Juran (1998), “qualidade é a adequação ao uso e consiste nas características do produto que atendem às necessidades dos clientes e assim fornecem a satisfação em relação ao produto". O autor também apresenta outra definição: "qualidade significa ausência de deficiências".

A Fundação Nacional da Qualidade (FNQ, 2008 p.61) estabelece o significado de qualidade da seguinte forma: "Qualidade é a totalidade de características de uma entidade (atividade ou processo, produto), organização, ou uma combinação destes, que lhe confere a capacidade de satisfazer as necessidades explícitas e implícitas dos clientes e demais partes interessadas".

Muitos são os estudos em torno do conceito de qualidade e apesar das diferentes tentativas, contextualizações ou explicações, há um denominador comum que é o cliente. Mesmo que inconsciente, desde a era da inspeção, onde a preocupação maior era na fabricação correta, o usuário sairia ganhando ao adquirir um produto melhor.

Corroborando esta afirmação, Ghobadian et al (1994) confirmam que a maioria das definições de qualidade irão recair na abordagem baseada no usuário, afirmando que a qualidade percebida pelo cliente deve corresponder ou superar suas expectativas.

Também, evidenciando o cliente como parte interessada e fundamental no conceito, as cinco abordagens de Garvin são resumidas por Slack et al (2008) na seguinte definição: "Qualidade é a consistente conformidade com as expectativas dos consumidores." 
Conformidade e expectativa são as palavras chaves da qualidade. A primeira expressa claramente o atendimento a uma especificação ou norma seja no processo de manufatura ou de serviço. A segunda nos remete ao termo percepção, que difere da exigência ou necessidade do cliente, fazendo entender que estes estão incorporados ao processo e que também avaliam a qualidade pela maneira como percebem e se satisfazem com um produto ou serviço, provocando e promovendo a melhoria contínua dos processos.

\subsection{A qualidade e os serviços}

O entendimento do que é qualidade em serviços para o cliente, pode ajudar a empresa a introduzir modificações e buscar melhorias de qualidade em seus produtos e serviços (ROCHA, 1999). Para uma melhor compreensão da qualidade em serviços, é primordial conhecer a definição de serviços.

De acordo com Fitzsimmons e Fitzsimmons (2005), há muitas definições diferentes de serviços, embora todas contenham a intangibilidade e o consumo simultâneo como temas comuns. Para os autores, serviço é uma experiência perecível, intangível, desenvolvida para um consumidor que desempenha o papel de co-produtor. Las Casas (2002) define serviço como algo que deve ser vivenciado; é uma experiência vivida, é o desempenho que se transfere.

Para Gianesi \& Corrêa (1994) serviços são experiências que o cliente vivencia, são produzidos e consumidos simultaneamente. Kotler, Hayes \& Bloom (2002), definem serviço "como uma ação, desempenho ou ato que é essencialmente intangível e não resulte necessariamente na propriedade do quer que seja e sua criação pode ou não estar vinculada a um produto material". Para Bateman \& Snell (1998), serviço ao consumidor é oferecer ao cliente o que ele quer ou necessita, do modo como quer da primeira vez.

Os serviços oferecidos por uma empresa devem ser cuidadosamente planejados e acima de tudo oferecidos com qualidade. A boa prestação de serviços gera satisfação aos clientes atendidos, que voltam a comprar ou indicam outras pessoas de seu relacionamento, aumentando a demanda e consequentemente os lucros.

A análise da qualidade dos serviços está diretamente relacionada à expectativa e percepção dos clientes. Segundo Kotler, Hayes \& Bloom (2002), "qualidade é a prestação de um serviço que supere as expectativas do cliente", ou seja, o fator essencial é superar a expectativa dos clientes quanto à qualidade de serviço.

A qualidade em serviços é um importante diferencial e deve ser avaliado constantemente, por isso o prestador de serviços deve sempre estar atento se o seu cliente está satisfeito com o atendimento recebido, comparando as expectativas do cliente com a avaliação do serviço oferecido. 
A opinião do cliente contribui muito para revelar a medida certa da qualidade dos produtos e serviços.

\section{2 .2 Expectativas dos clientes e percepção da qualidade de serviços}

A comparação entre as expectativas do consumidor antes da prestação do serviço e a experiência do consumidor decorrente do uso do serviço encontra suporte teórico no chamado “paradigma de desconfirmação". Segundo Spreng e Olshavsky (1993), este paradigma mede a expectativa do cliente após a exposição do produto. Boulding et al (1993), afirmam que o paradigma compara as expectativas antes e depois da exposição do produto ou serviço. Para Gardial et al (1994), o paradigma consiste em entrevistas pessoais que buscam comparar produtos entre si ou com outras pessoas e outras experiências de consumo.

Deste modo, o consumidor estará satisfeito ou insatisfeito conforme esteja o desempenho do prestador do serviço, respectivamente, abaixo ou acima de suas expectativas.

Para Loverlock e Wright (2007), as definições baseadas nos serviços igualam qualidade à satisfação do cliente, conforme define a equação:

\section{SATISFAÇÃO = SERVIÇO PERCEBIDO / SERVIÇO ESPERADO}

As expectativas dos clientes podem variar entre diferentes grupos demográficos, como homens e mulheres, consumidores mais velhos e mais jovens, trabalhadores de escritórios e de fábricas, atletas e freqüentadores de academias, classe, religião, países, regiões etc.

Zeithml et al, 1990 (apud CORREA e CAON, 2009) afirmam que as expectativas do cliente são formadas com base nos seguintes fatores: necessidades e desejos do cliente, a experiência passada do próprio cliente, a comunicação boca a boca, a comunicação externa (incluída aí a propaganda da própria organização) e o preço - Figura 1.

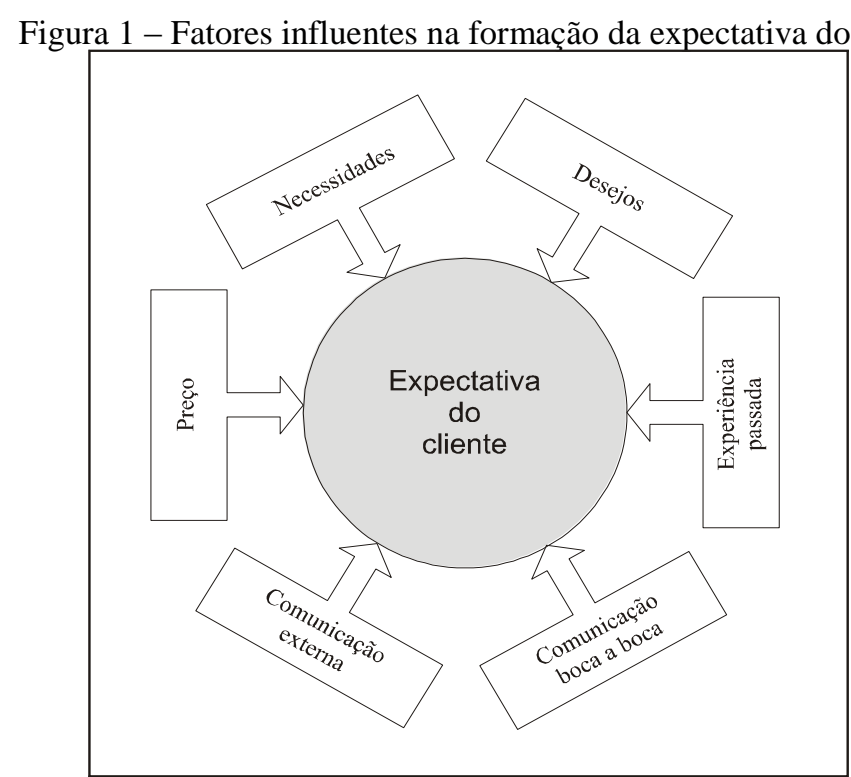

Fonte: adaptada de Zeithaml et al (1990) 
Ao conhecermos os fatores influenciadores da expectativa do cliente podemos então indagar: qual o nível de influência de cada fator na construção da expectativa? A diferença que se estabelece então, entre o que o consumidor crê poder ser e o que deveria ser a prestação do serviço, conceitua a zona de tolerância. Rodrigues (2001, p.114), citando Berry, Parasuraman e Zeithaml, diz que esta zona pode se dilatar ou contrair como um acordeão.

Corrêa e Caon (2009) corroboram essa afirmação e explicam que as expectativas dos clientes, na verdade, não se encontram em um nível só, bem definido e claro. Há uma faixa de expectativas com as quais o cliente trabalha, definida em função das variáveis: intolerável, mínimo tolerável, justo, desejável, máximo possível e perfeito. Apoiados nestas variáveis, os autores representam a faixa de expectativa e limites de aceitabilidade, mostrando que estas não constituem um ponto fixo, mas uma zona de desempenhos esperados pelos clientes, como aceitável e não aceitável, que pode ser melhor observado na figura 2.

Figura 2 - Variáveis, faixa de expectativas e limites de aceitabilidade

\begin{tabular}{|c|c|c|}
\hline Perfeição & Ideal absoluto de serviço perfeito \\
\hline Máximo possível & O máximo viável & \\
\hline Desejável & Um bom padrão & \\
\hline Justo & Um padrão justo pelo preço & $\begin{array}{c}\text { Expectativas } \\
\text { são faixas e } \\
\text { não pontos }\end{array}$ \\
\hline Mínimo tolerável & Padrão mínimo tolerável & \\
\hline Intolerável & Padrão fora do limite tolerável. & Baixas \\
\hline
\end{tabular}

Fonte: adaptada de Corrêa e Caon (2009)

\subsection{A qualidade dos serviços e as academias de ginástica}

A crescente insatisfação dos clientes com a qualidade marcou os anos 80 . Não somente pela especificação de produtos industrializados, mas também pelo mau atendimento no PDV (ponto de venda) ou na pós-venda. A grande dificuldade na resolução de problemas que envolviam a percepção e retorno dos clientes no que se referem a reembolsos, trocas, contato direto ou por telefone invadiram vários ramos de atividades como bancos, hotéis, concessionárias, supermercados, restaurantes, etc. como também academias de ginástica e musculação. Acionistas e clientes tornaram-se conscientes de que a qualidade era um bom negócio para ambas as partes.

De acordo com Loverlock (2001), hove uma mudança radical no pensamento. Noções tradicionais de qualidade (baseadas na conformidade com padrões definidos por gerentes operacionais) foram substituídas pelo novo imperativo de deixar a qualidade ser dirigida pelo 
cliente, o que trouxe enormes conseqüências para a importância do serviço e o papel da pesquisa junto aos clientes.

Ao relacionar tais evidências com a gestão de academias é possível identificar a necessidade de mudança neste setor. Resgatando historicamente o modelo de gestão neste tipo de empresa Venlioles (2005) apresenta as seguintes observações:

\begin{abstract}
"O verdadeiro motivo dos freqüentes insucessos de algumas empresas é a falta de preparo administrativo dos empresários de atividade física. O que falta ao modelo de gestão são empresários com capacidade de olhar, ver e entender o seu próprio estabelecimento de atividade física, monitorando continuamente, identificando oportunidades, mudança de cenários e problemas." (VENLIOLES, 2005, p.15).

"Diante desse quadro, todos os estabelecimentos de atividade física que quiserem permanecer no mercado deverão se enquadrar nessa nova idéia de gestão voltada para o cliente, utilizando os conceitos de qualidade total. Esse conceito dominará o cenário em todos os estabelecimentos nos próximos anos, forçando-os a se engajarem nesse esforço, sob o risco de perderem os clientes. Os estabelecimentos de atividade física que praticam o modelo de gestão voltado para o cliente retêm e captam novos clientes, além de ampliar a lucratividade" (VENLIOLES, 2005, p.16).
\end{abstract}

Muitas academias são abertas a cada ano, mas também muitas destas fecham suas portas e nem sempre as causas são estudadas, talvez um modelo de gestão da qualidade bem implementado seja uma das soluções para a sua perenidade, entendendo que paralelo ao sistema de gestão elas preencham pré-requisitos básicos complementares ao seu sucesso como: localização, preço, equipamentos, diversidade de aulas e opções de consumo, legalização, equipe profissional, etc.

A prática regular de atividade física em academias constitui cerca de $2,7 \%$ da população, o que torna o mercado praticamente "virgem". A recente regulamentação da profissão e criação dos Conselhos Federal e Regional (CONFEF - CREF) agregou um novo valor à profissão que passou a ser reconhecida e solicitada pela sociedade de uma forma mais confiante.

De acorco com Saba(2004), entre os anos de 1999 a 2009, a profissão cresceu e vem sendo enaltecida e recomendada pela classe médica, fisioterapeutas, nutricionistas, psicólogos, psiquiatras, etc. Logo é um setor "novo" e com grande potencial em expansão. Mas, ainda, se caracteriza pela atuação amadora e o desempenho pífio. Sob o enfoque do autor os gestores de academias privilegiam excessivamente a aquisição de equipamentos, novas modalidades e recursos técnicos, ou seja, os clientes internos e externos são pouco considerados na cultura organizacional. Parece paradoxo, tendo em vista que se a implementação de novas tecnologias visa á satisfação dos clientes, estes deveriam ser pelo menos consultados, tanto os internos quanto os externos.

\title{
2.4 Dimensões de qualidade
}

Parasuraman, Zeithaml e Berry (1991) propõem cinco dimensões da qualidade utilizadas pelos clientes para julgar os serviços que lhes são prestados: a tangibilidade, a responsabilidade, a confiabilidade, a empatia e a garantia. Segundo Fitzssimons e Fitzsimmons (2005), os clientes 
utilizam estas dimensões para fazer julgamentos em relação à qualidade dos serviços oferecidos, através da comparação entre o serviço efetivamente prestado e o serviço percebido, sendo que a diferença entre ambos constitui uma medida de qualidade, sendo a satisfação negativa ou positiva.

As dimensões da qualidade formam a base para a construção do método de avaliação da qualidade SERVQUAL. Inicialmente Parasuraman et al (1985) propuseram dez dimensões da qualidade em serviço: tangibilidade, responsabilidade, confiabilidade, acessibilidade, compreensão do cliente, comunicação, competência, segurança, cortesia e credibilidade. De acordo com Fitzssimons e Fitzsimmons (2005), atualmente, as 5 dimensões que compõem a ferramenta Servqual são as seguintes:

- Tangibilidade: Representa fundamentalmente a aparência de tudo o que envolve a prestação de serviços. Bateson (2001) relaciona como itens tangíveis de uma empresa objetos que são utilizados em seu interior, desde decoração até a apresentação e aparência de seu quadro de funcionários;

- Responsabilidade: Bateson (2001) conceitua esta dimensão como receptividade. Ela é responsável por mensurar a receptividade da empresa e seus funcionários para com seus clientes de maneira e em horário oportunos.

- Confiabilidade : Bateson (2001) afirma que "nada pode ser mais frustrante para os clientes do que os prestadores de serviço não-confiáveis”. Lovelock e Bateson são unânimes em dizer que a confiabilidade é a dimensão mais importante para o consumidor de serviços. Uma empresa que não tem confiabilidade perante seus clientes está fadada ao insucesso;

- Empatia: Empatia significa a capacidade de uma pessoa em vivenciar os sentimentos de outra. Atenção, cuidado e interesse personalizados para o cliente. Bateson (2001) também sugere que a empresa que possui esta dimensão "nunca perde de vista o que é ser um cliente da sua empresa".

- Garantia: Esta dimensão abrange a competência, cortesia e certeza da empresa. A competência relaciona-se ao conhecimento, habilidade da empresa em prestar o serviço. A cortesia espelha como os funcionários agem com seus clientes e seus pertences e a certeza é o que o cliente precisa para saber que está, inclusive fisicamente, seguro (BATESON, 2001);

Através da figura 3, entendemos ainda mais a relação entre serviço esperado (SE) e serviço percebido (SP) em conforme as dimensões da qualidade e a classificação dos serviços em surpreendente, satisfatório e inaceitável, já citada anteriormente neste estudo. 
Figura 3 - Qualidade Percebida do Serviço

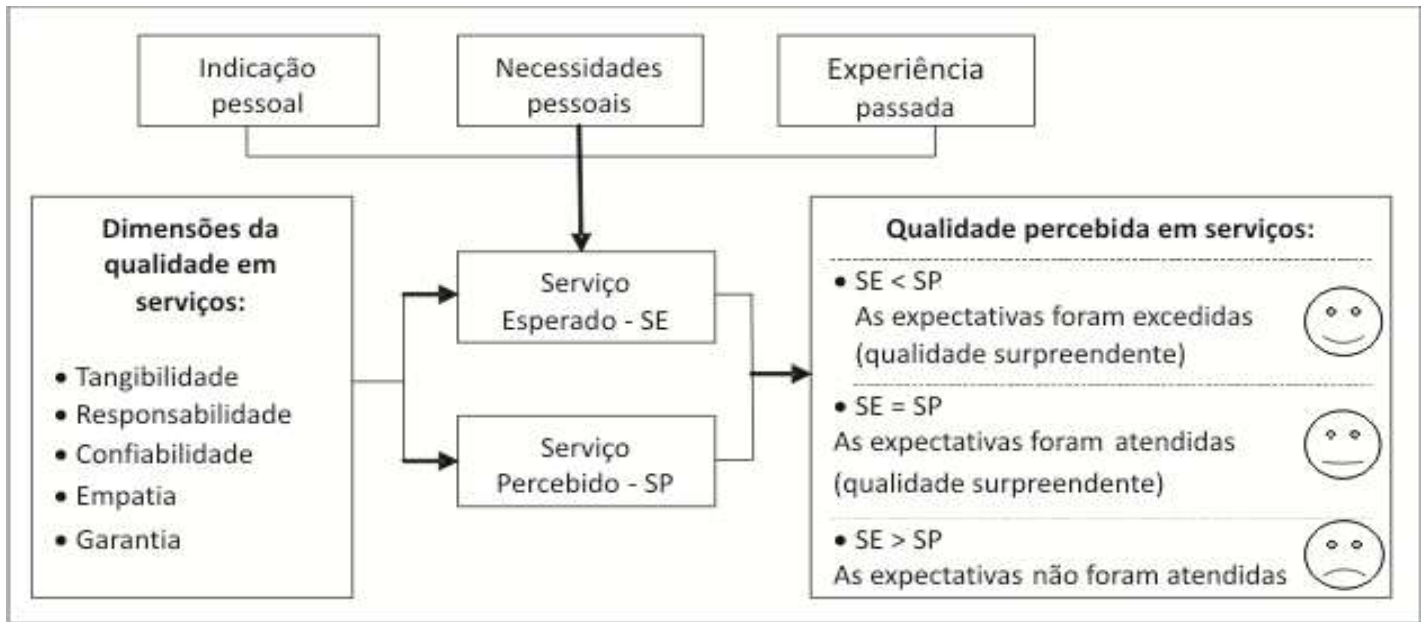

Fonte: Adaptação de Parasuraman, Zeithaml e Berry.

\subsection{O método servqual}

O método SERVQUAL desenvolvido por Parasuraman, Zeithami e Berry (1985) consiste numa ferramenta capaz de medir o nível da qualidade dos serviços prestados. O procedimento de mensuração se dá por meio da diferença de escores obtidos através de um questionário, que aborda as cinco dimensões da qualidade em serviços: tangibilidade, responsabilidade, confiabilidade, empatia e garantia.

O questionário SERVQUAL possui 22 questões para mensurar as cinco dimensões da qualidade de serviços. Estas questões são avaliadas em uma escala Likert de 5 ou 7 pontos ("discordo totalmente" a "concordo totalmente"). Concebido originalmente em duas seções (uma para avaliar as expectativas do consumidor,outra para avaliar suas percepções em relação à prestação de um determinado serviço. A avaliação da qualidade dos serviços é dada pela diferença entre o desempenho do serviço prestado e a expectativa do cliente em relação ao serviço recebido

O método Servqual proporcionará uma pontuação que poderá ser positiva, negativa ou neutra, de acordo com a média obtida pela respostas dos entrevistados para cada questão. Segundo Loverlock e Wrigt (2007), quando a qualidade real cai abaixo do nível de serviço adequado esperado pelos clientes, ocorre um gap - ou lacuna na qualidade - entre o desempenho do fornecedor de serviços e as expectativas do cliente.

Parasuraman et al., citados anteriormente, afirmam que, independentemente do tipo de serviço, os critérios utilizados pelos clientes para avaliar a qualidade do serviço percebida serão muito semelhantes. Vários pesquisadores, reconhecem que o SERVQUAL precisa de adpatação e que pode ser aperfeiçoado. Por exemplo, Carman (1990), Finn e Lamb (1991), Babakus e Boller (1992) e Brown et al (1993) alegam que o instrumento SERVQUAL deve ser personalizado, talvez, incluindo dimensões adicionais que são específicas para o serviço ou indústria em questão. Desta 
forma, o instrumento de coleta, apesar de manter as mesmas características, sempre sofrerá mudanças na quantidade de questões e dimensões analisadas.

\section{Metodologia}

A pesquisa é qualitativa e de caráter descritivo, por tratar-se de um estudo claramente definido quanto ao campo e a dimensão a ser trabalhada. A característica da pesquisa de campo se dá por existir um ambiente definido para as buscas das informações, sendo as academias de ginástica,

Neste aspecto é intenção compreender melhor o fenômeno da gestão da qualidade em academias em relação à satisfação dos clientes, através da percepção dos indivíduos envolvidos na circunstância analisada, para uma possível interpretação desta realidade.

A pesquisa bibliográfica foi desenvolvida a partir de materiais anteriormente elaborados em periódicos, artigos científicos, livros, revistas, entre outros, tornando-se um referencial teórico para o estudo de caso.

Para a pesquisa de campo foi desenvolvido um questionário tendo por base a escala SERVQUAL. Concebido em duas seções: uma para avaliar as expectativas do cliente, outra para avaliar suas percepções após a utilização dos serviços da academia. O questionário SERVQUAL possui 22 questões para mensurar as cinco dimensões de qualidade de serviços, que foram adaptadas para este estudo e distribuídas neste da seguinte forma: tangibilidade (4 questões); responsabilidade (4 questões); confiabilidade (4 questões); empatia (4 questões) e garantia (6 questões). Estas em uma escala de 5 a 0 pontos, sendo que estes números variam de nível elevado à baixo.

\section{Características da empresa estudada}

A academia, objeto de estudo, fundada há 26 anos, localiza-se em um bairro de classe média na cidade de João Pessoa, capital do estado da Paraíba, com estrutura e capacidade para atender confortavelmente 400 usuários. Possui atualmente cerca de 270 clientes, diversificados em relação a sexo e faixa etária. Funciona de segunda a sexta-feira nos horários de 6:00h às 11:00h e das 14:00h às 21:30h. Oferece aos clientes as seguintes atividades: musculação, ergometria, ginástica, cycling indoor, step training, jump, ritmos, star mix, up training, aerobic express, pilates e grupo de convivência para "melhor idade". Possui nutricionista e serviço de avaliação física terceirizados. Tem como missão: encantar o cliente proporcionando qualidade de vida através do exercício físico em ambiente saudável e acolhedor.

Em outubro de 2007 a empresa iniciou um processo de adequação das sistemáticas internas de trabalho aos requisitos de um Sistema de Gestão da Qualidade, que proporcionou toda uma reestruturação gerencial da empresa, implicando em investimentos e aporte de recursos que 
envolveram: melhoria das condições de trabalho; investimentos em treinamentos para os colaboradores; suprimento de equipamentos; organização dos processos internos; definição de metas e aprimoramento das metodologias de gerenciamento, dentre outras atividades.

No decorrer do estudo observaram-se diversos aspectos positivos, dentre os quais as instalações, manutenção de equipamentos, nível de formação dos colaboradores, bem como a coragem, vontade e persistência da alta direção em desenvolver ações que promovam a empresa em tentar acertar e fazer sempre o melhor. Os recursos/equipamentos oferecidos são todos de qualidade razoável e estão em bom estado de conservação, oferecendo segurança e satisfação básica aos clientes.

\section{Resultados e discussões}

Aplicou-se o questionário SERVQUAL numa amostra composta por 92 usuários. A partir dos dados obtidos, observou-se que 59\% da amostra é do sexo feminino e $41 \%$ do sexo masculino. A faixa etária dos entrevistados foi entre 14 a 72 anos, apresentando uma média de idade de 34 anos.

Da amostra inicial de 92 entrevistas realizadas, 71 usuários responderam corretamente, ou seja, apenas $77 \%$ dos questionários foram validados. Os valores correspondentes às respostas dos questionários foram tabulados de acordo com as dimensões analisadas (Quadro 1), utilizou-se estatística descritiva para a análise das questões propostas.

Quadro 1 - Respostas obtidas nos questionário - Expectativa x Desempenho levando em cosideração as dimensões da qualidade

\begin{tabular}{|c|c|c|c|c|c|c|c|c|c|c|c|c|c|c|c|}
\hline \multirow{3}{*}{ Questão } & \multicolumn{7}{|c|}{ EXPECTATIVA } & \multicolumn{7}{|c|}{ PERCEPÇÃO } & \multirow{3}{*}{ DIMENSÕES } \\
\hline & \multicolumn{5}{|c|}{ Respostas Obtidas } & \multirow{2}{*}{ Média } & \multirow{2}{*}{$\begin{array}{c}\text { Desvio } \\
\text { Padrão }\end{array}$} & \multicolumn{5}{|c|}{ Respostas Obtidas } & \multirow{2}{*}{ Média } & \multirow{2}{*}{$\begin{array}{l}\text { Desvio } \\
\text { Padrão }\end{array}$} & \\
\hline & 1 & 2 & 3 & 4 & 5 & & & 1 & 2 & 3 & 4 & 5 & & & \\
\hline 1 & 2 & 5 & 13 & 25 & 26 & 3,9577 & 1,0479 & 2 & 0 & 9 & 32 & 28 & 4,1831 & 0,8670 & \multirow{4}{*}{ Tangibilidade } \\
\hline 2 & 0 & 1 & 17 & 22 & 30 & 4,0986 & 0,9733 & 0 & 0 & 7 & 19 & 44 & 4,4648 & 0,8591 & \\
\hline 3 & 4 & 0 & 14 & 26 & 27 & 4,0141 & 1,0487 & 2 & 7 & 30 & 15 & 17 & 3,5352 & 1,0533 & \\
\hline 4 & 0 & 0 & 7 & 19 & 45 & 4,5352 & 0,6725 & 0 & 0 & 8 & 20 & 43 & 4,4930 & 0,6943 & \\
\hline 5 & 0 & 0 & 7 & 33 & 31 & 4,3380 & 0,6534 & 0 & 0 & 8 & 20 & 43 & 4,4930 & 0,6943 & \multirow{4}{*}{ Responsabilidade } \\
\hline 6 & 2 & 2 & 8 & 26 & 33 & 4,2113 & 0,9549 & 2 & 1 & 18 & 27 & 23 & 3,9577 & 0,9477 & \\
\hline 7 & 0 & 4 & 8 & 22 & 37 & 4,2958 & 0,8847 & 0 & 8 & 12 & 23 & 28 & 4,0000 & 1,0142 & \\
\hline 8 & 0 & 3 & 8 & 23 & 37 & 4,3239 & 0,8413 & 0 & 4 & 4 & 10 & 53 & 4,5775 & 0,8394 & \\
\hline 9 & 0 & 0 & 4 & 31 & 36 & 4,4507 & 0,6045 & 0 & 1 & 4 & 23 & 43 & 4,5211 & 0,6731 & \multirow{4}{*}{ Confiabilidade } \\
\hline 10 & 0 & 1 & 4 & 16 & 50 & 4,6197 & 0,6626 & 0 & 0 & 0 & 8 & 63 & 4,8873 & 0,3184 & \\
\hline 11 & 0 & 3 & 9 & 17 & 42 & 4,3803 & 0,8679 & 0 & 2 & 11 & 18 & 40 & 4,3521 & 0,8468 & \\
\hline 12 & 0 & 0 & 7 & 24 & 40 & 4,4648 & 0,6725 & 0 & 0 & 3 & 29 & 39 & 4,5070 & 0,5824 & \\
\hline 13 & 0 & 3 & 10 & 26 & 32 & 4,2254 & 0,8485 & 0 & 2 & 3 & 25 & 41 & 4,4789 & 0,7143 & \multirow{4}{*}{ Empatia } \\
\hline 14 & 0 & 1 & 9 & 15 & 46 & 4,4930 & 0,7723 & 0 & 0 & 0 & 18 & 53 & 4,7465 & 0,4381 & \\
\hline 15 & 1 & 3 & 10 & 11 & 46 & 4,3803 & 0,9764 & 2 & 3 & 18 & 11 & 37 & 4,0986 & 1,0975 & \\
\hline 16 & 0 & 4 & 9 & 19 & 39 & 4,3099 & 0,9038 & 2 & 4 & 15 & 16 & 34 & 4,0704 & 1,0866 & \\
\hline 17 & 0 & 0 & 0 & 25 & 46 & 4,6479 & 0,4810 & 0 & 0 & 0 & 18 & 53 & 4,7465 & 0,4381 & \multirow{6}{*}{ Garantia } \\
\hline 18 & 0 & 1 & 4 & 11 & 55 & 4,6901 & 0,6457 & 0 & 0 & 4 & 18 & 49 & 4,6338 & 0,5914 & \\
\hline 19 & 0 & 0 & 3 & 23 & 45 & 4,5915 & 0,5751 & 1 & 0 & 3 & 17 & 50 & 4,6197 & 0,7044 & \\
\hline 20 & 0 & 2 & 4 & 33 & 32 & 4,3380 & 0,7160 & 1 & 3 & 2 & 14 & 51 & 4,5634 & 0,8574 & \\
\hline 21 & 0 & 0 & 4 & 17 & 50 & 4,6479 & 0,5879 & 0 & 0 & 0 & 14 & 57 & 4,8028 & 0,4007 & \\
\hline 22 & 0 & 2 & 8 & 23 & 38 & 4,3662 & 0,7971 & 0 & 5 & 7 & 22 & 37 & 4,2817 & 0,9131 & \\
\hline
\end{tabular}


Fonte: Dados da Pesquisa

Os valores médios para as expectativas dos clientes variaram de 3,9577 a 4,6901. A concentração das respostas em torno do nível 4 indica que os usuários apresentam níveis altos de expectativas em relação aos serviços. Entre as expectativas com níveis mais altos se destacam:

- Condições físicas do ambiente favoráveis à prestação do serviço, como limpeza e organização;

- Conhecimento técnico dos profissionais;

- Cortesia e boa educação dos colaboradores;

- Prescrição de exercícios feita com base na avaliação física;

- Credibilidade na avaliação física realizada na academia;

- Conhecimento dos colaboradores para responder perguntas dos clientes.

É importante destacar que a afirmativa com média de expectativa mais elevada $(4,6901)$ está relacionada à prescrição de exercícios feita com base na avaliação física, que pode ser explicada pela própria natureza do serviço prestado na academia, onde o resultado físico obtido se dá em função dos exercícios prescritos. Ressalta-se também que 66,67\% das médias mais elevadas de expectativa (acima de 4,5) encontram-se na dimensão garantia, superando as dimensões confiabilidade e tangibilidade, que somadas alcançaram 33,33\% destas médias, como também responsabilidade e empatia, que não contabilizaram médias elevadas de expectativa.

Dentre os itens com expectativas menos elelevadas (entre 3,95 e 4,32) destacam-se:

- Ambiente atraente e visualmente agradável;

- Funcionários com boa paarência e com uso de uniformes;

- Equipamentos modernos e eficientes;

- Quantidade suficiente de funcionários para atender prontamente a demanda;

- Capacidade de reparar uma falha com eficiência e rapidez;

- Atenção individual e personalizada, demonstrando interesse da academia com o bem estar dos clientes.

Tais afirmativas apontam que os clientes não atribuem prioriddade à aparência das instalações e dos funcionários, nem ao atendimento personalizado e à disponibilidade dos funcionários para atender seus pedidos, o que não significa que considere, esses itens satisfatórios.

Com relação ao desempenho observado, ou seja, á percepção do cliente em relação ao serviço prestado, os valores médios variaram de 3,5352 a 4,8873. Entre as afirmativas que epresentaram níveis mais altos de percepção (entre 4,2 e 5,0), destacam-se:

- Disposição para ajudar os clientes nos momentos de dificuldade;

- Comprometimento da academia em desempenhar suas tarefas; 
- Conhecimento técnico dos profissionais;

- Prestação de serviços corretos e confiáveis;

- Compreensão da academia em prescrever atividades que atendam necessidades específicas, respeitando a individualidade biológica do cliente;

- Cortesia e boa educação dos colaboradores;

- Prescrição dos exercícios feita com base na avaliação física;

- Credibilidade na avaliação física da academia;

- Comunidação permanente entre a academia e clientes;

- Conhecimento dos colaboradores para responder perguntas dos clientes.

Os resultados mostraram que os clientes percebem com níveis mais altos $50 \%$ dos aspectos que eles consideraram mais relevantes nas suas expectativas, ressaltando que cinco destes compõem a dimensão garantia, maior destaque nas expectativas.

Observou-se ainda que seis itens apresentaram médias de percepção abaixo de 4,2, a saber:

- Ambiente atrante e visualmente agradável;

- Equipamentos modernos e efeicientes;

- Quantidade suficiente de funcionários para atender prontamente a demanda;

- Capacidade de reparar uma falha com eficiência e rapidez;

- Horário de funcionamento conveniente aos clientes;

- Facilidade de acesso e estacionmento.

Ressalta-se que quatro destes itens obtiveram médias baixas nas expectativas dos clientes o que demonstra certa coerência na resposta dos questionários. Analisando de forma mais geral as respostas dos clientes, pode-se considerar que as notas atribuídas concentraram-se em sua maioria no intervalo entre 3 e 5 , tanto as relativas à expectativa quanto às perceptivas.

Analisando a qualidade percebida pelo cliente, de acordo com o que estabelece o método SERVQUAL, a qualidade dos serviços foi calculada pela diferença, percepções - expectativas, utilizando-se para isso as médias das pontuações atribuídas a cada afirmativa nos módulos Percepções e Expectativas. As diferenças entre as médias, expressas no Quadro 2, variaram de 0,4789 a 0,3662 , onde os valores positivos apontaram avaliações de qualidade satisfatória e os negativos o inverso. 
Quadro 2 - Qualidade percebida segundo cada item do questionário

\begin{tabular}{|c|c|c|c|}
\hline ITEM & $\begin{array}{c}\text { QUALIDADE PERCEBIDA } \\
\text { (Diferença entre as médias da } \\
\text { expectativa e desempenho) }\end{array}$ & ITEM & $\begin{array}{c}\text { QUALIDADE PERCEBIDA } \\
\text { (Diferença entre as médias da } \\
\text { expectativa e desempenho) }\end{array}$ \\
\hline $\mathbf{1}$ & 0,2254 & $\mathbf{1 2}$ & 0,0423 \\
\hline $\mathbf{2}$ & 0,3662 & $\mathbf{1 3}$ & 0,2535 \\
\hline $\mathbf{3}$ & $-0,4789$ & $\mathbf{1 4}$ & 0,2535 \\
\hline $\mathbf{4}$ & $-0,0423$ & $\mathbf{1 5}$ & $-0,2817$ \\
\hline $\mathbf{5}$ & 0,1549 & $\mathbf{1 6}$ & $-0,2394$ \\
\hline $\mathbf{6}$ & $-0,2535$ & $\mathbf{1 7}$ & 0,0986 \\
\hline $\mathbf{7}$ & $-0,2958$ & $\mathbf{1 8}$ & $-0,0563$ \\
\hline $\mathbf{8}$ & 0,2535 & $\mathbf{1 9}$ & 0,0282 \\
\hline $\mathbf{9}$ & 0,0704 & $\mathbf{2 0}$ & 0,2254 \\
\hline $\mathbf{1 0}$ & 0,2676 & $\mathbf{2 1}$ & 0,1549 \\
\hline $\mathbf{1 1}$ & $-0,0282$ & $\mathbf{2 2}$ & $-0,0845$ \\
\hline
\end{tabular}

Fonte: Dados da Pesquisa

Observou-se que nove das vinte e duas afirmações apresentaram valores negativos, no entanto quatro delas estavam muito próximas de zero. Destacaram-se os seguintes itens que apresentaram qualidade percebida não satisfatória:

- Equipamentos modernos e efeicientes;

- Quantidade suficiente de funcionários para atender prontamente a demanda;

- Capacidade de reparar uma falha com eficiência e rapidez;

- Horário de funcionamento conveniente aos clientes;

- Facilidade de acesso e estacionmento.

Partindo para uma análise da qualidade percebida pelo cliente segundo as cinco dimensões da qualidade obteve-se o Quadro 3, onde a qualidade observada nas dimensões Responsabilidade e Empatia apresentou-se como não satisfarória. No entanto, cabe ressaltar que todas as dimensões apresentaram valores muito próximos de zero, o que sinaliza que a qualidade percebida foi bem próxima da esperada.

Quadro 3 - Qualidade percebida segundo as cindo dimenões da qualdiade

\begin{tabular}{|c|c|}
\hline DIMENSÕES & $\begin{array}{c}\text { QUALIDADE PERCEBIDA } \\
\text { (Diferença entre as médias da } \\
\text { expectativa e desempenho) }\end{array}$ \\
\hline Tangibilidade & 0,0176 \\
\hline Responsabilidade & $-0,0352$ \\
\hline Confiabilidade & 0,0880 \\
\hline Empatia & $-0,0035$ \\
\hline Garantia & 0,0610 \\
\hline
\end{tabular}

Fonte: Dados da Pesquisa 


\section{Considerações Finais}

São muitas as razões que levaram a investigação e aprofundamento do tema proposto. A começar pelo crescente número de novas academias de ginástica e conseqüentemente da demanda pelos serviços oferecidos neste tipo de empreendimento, mas sobretudo pela alta rotatividade, ou seja, pela grande dificuldade apresentada na retenção de clientes. No caso específico da academia estudada percebeu-se, a partir da aplicação do método SERVQUAL, que as dimensões tangibilidade, confiabilidade e garantia superaram as expectativas dos clientes, tendo em vista que a diferença entra as médias das qualidades esperadas e observadas foram positivas.

A dimensão tangibilidade, cuja qualidade percebida foi de 0,0176, representa fundamentalmente a aparência de tudo o que envolve a prestação de serviços. Outra dimensão que merece destaque dentre as que superaram as expectativas dos clientes, alcançando 0,0880 na qualidade percebida, é a confiabilidade. De acordo com Lovelock (2001) e Bateson (2001), esta é a dimensão mais importante para o consumidor de serviços. Tal dimensão diz respeito a capacidade para realizar o serviço prometido de forma correta. Outro aspecto positivo da avaliação diz respeito á dimensão garantia, que obteve 0,0610 na qualidade percebida pelos clientes. Segundo Bateson (2001), esta dimensão abrange a competência, cortesia e certeza da empresa.

As dimensões responsabilidade e empatia, relacionadas respectivamente à receptividade da empresa e funcionários e à atenção, cuidado e interesse personalizados para o cliente, não alacançaram uma qualidade percebida positiva. No entanto, sugere-se, atenção a estas dimensões, mas sem tanta preocupação, pois seus valores, apesar de serem negativos, ficaram muito próximos de zero. Este aspecto, valores muito próximos de zero, algo que deve ser revisto na aplicação e análise do método SERVQUAL em estudos futuros.

Finalmente, pode-se afirmar que as expectativas dos clientes da academia analisada foram atendidas em quase todas as dimensões da qualidade o que indica que estes estão satisfeitos com o serviço prestado pela academia.

\section{Referências}

BATALHA, M. O. (Org.) Introdução à Engenharia de Produção. Rio de Janeiro: Elsevier, 2008.

BATESON, JOHN E.G. \& HOFFMAN, K. DOUGLAS. Marketing de serviços. 4. ed. Porto Alegre: Bookman, 2001.

BATEMAN, THOMAS S \& SNELL, SCOTT A. Administração: construindo vantagem competitiva. São Paulo: Atlas, 1998, p.80-147.

BABAKUS, E. \& BOLLER, G. W. An empirical assessment of the SERVQUAL scale. Journal of Business Research v. 24, 253-268. 1992.

\section{cross ref}

BOULDING, W.; KALRA, A; STAELIN, R.; ZEITHAML, V.A. A dynamic process model of service quality: from expectations to behavioral intentions. Journal of Marketing Research, v. 30, p. 7-27, 1993.

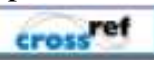


BROWN, T. S.; CHURCHILL, G. A. \& PETER, J. P. Research note: improving the measurement of service quality. Journal of Retailing, v.69, p. 127-139, 1993.

cross ref

CARMAN, J. M. (1990) Consumer perceptions of service quality: an assessment of the SERVQUAL Dimensions. Journal of Retailing, v. 66, 33-55.

CORREA, HENRIQUE L \& CAON, MAURO. Gestão de serviços: lucratividade por meio de operações e de satisfação dos clientes. $1^{\mathrm{a}}$ ed, São Paulo: Atlas, 2009.

ELEUTÉRIO, SUELI A. V. \& SOUZA, MARIA C. A. F. Qualidade na prestação de serviços: Uma avaliação com clientes internos. Cadernos de Pesquisa em Administração. São Paulo. v. 09, n 3. julho/setembro, 2002.

FITZSIMMONS, JAMES A. \& FITZSIMMONS MONA J. Administração de Serviços: operações, estratégia e tecnologia da informação. $4^{\mathrm{a}}$ Ed. São Paulo: Bookman, 2005.

FNQ. Cadernos Rumo à Excelência: Introdução ao Modelo de Excelência da Gestão (MEG). São Paulo: FNQ, 2008.

FNQ. Critérios compromisso com a excelência e rumo à excelência. São Paulo: FNQ, 2009.

GIANESI,IRINEU G.N. \& CORRÊA, HENRIQUE LUIZ. Administração e estratégica de serviços. São Paulo: Atlas, p. $233,1994$.

GHOBADIAN, ABBY; SPELLER, SIMON \& JONES, MATTHEW. Service quality; concepts and models. International Journal of. Quality \& Reliability Manegement., v. 11, p. 43-66, 1994.

KOTLER, PHILIP; HAYES, THOMAS \& BLOOM, PAUL N. Marketing de serviços profissionais:estratégias inovadoras para impulsionar sua atividade, sua imagem e seus lucros. 2.ed.São Paulo: Manole, 2002, 551p.

JURAN, J. M. Juran na liderança pela qualidade, um guia para executivos. 2a Ed. São Paulo: Pioneira, 1993.

LAS CASAS, A. L. Qualidade total em serviços. 5ª Ed. São Paulo: Atlas, 2006.

LOVELOCK, C. Serviços: marketing e gestão. São Paulo: Saraiva, 2001.

LOVERLOCK, C.; WRIGHT, L. Serviços: marketing e gestão. São Paulo: Saraiva, 2007.

FINN, D. W.; LAMB, C. W. An evaluation of the SERVQUAL scale in a retail setting. In Holman, R. H; Solomon, M. R. (org.), Advances in Consumer Research, v. 18. Association for Consumer Research, Provo, UT, 1991.

GARDIAL, S. F. et al. Comparing Consumer's Recall of Prepurchase and Postpurchase Product Evaluation Experiences. Journal of Consumer Research, Gainesville, v. 20, n. 4, p. 548-560, Mar. 1994.

cross ref

PARASURAMAN, A; ZEITHAML, V. A.; BERRY, L. L. A conceptual modelo f service quality and its implications for future research. Journal of Marketing, v. 49, p. 41-50, 1985.

PEINADO, J.; GRAEML, A. R. Administração da produção: operações industriais e de serviços. Curitiba : UnicenP, 2007.

PEREIRA, M. Administração sem segredo: sua academia rumo ao sucesso. São Paulo: Phorte, 2005.

ROCHA, A. Da; CHRISTENSEN, C. Marketing: teoria e prática no Brasil. 2.ed. São Paulo: Atlas, p.89-91, 1999.

SABA, F.; ANTUNES, F. Gestão em atendimento: manual prático para academias e centros esportivos. São Paulo: Manole, 2004.

SABA, F.; PIMENTA, M. T. Vendas e retenção: 83 lições para academias e clubes desportivos. São Paulo: Phorte, 2008.

SLACK, N. Administração da produção; $2^{a}$ ed. São Paulo: Atlas, 2008. 
SPRENG, R. A.; OLSHAVSKY, R. W. A desires congruency model of consumer satisfaction. Journal of Academy of Marketing Science. v. 21, n. 3, p. 169-177, 1993.

cross ref

ZEITHML, V. A.; BITNER J. Marketing de serviços: a empresa com foco no cliente. $2^{\mathrm{a}}$ Ed. Porto Alegre: Bookman, 2003.

VENLIOLES, F. M. Manual do gestor de academia - Rio de Janeiro: Sprint, 2005

\section{Dados dos autores:}

Nome completo: Eduardo Guimarães Lima Barreto

Filiação institucional: Universidade Federal da Paraíba - UFPB

Departamento: Programa de Pós-Graduação em Engenharia de Produção

Função ou cargo ocupado: Mestrando

Endereço completo para correspondência (bairro, cidade, estado, país e CEP): Programa de Pós-

Graduação em Eng. de Produção/CT-UFPB Jardim Universitário s/n - Castelo Branco - João

Pessoa/PB - Brasil - CEP. 58.051-900

Telefones para contato: (83) 32167124

e-mail: eduardoguima@gmail.com

\section{Nome Completo: Roberta de Lourdes Silva dos Santos}

Filiação institucional: Universidade Federal da Paraíba - UFPB

Departamento: Programa de Pós-Graduação em Engenharia de Produção

Função ou cargo ocupado: Mestranda

Endereço completo para correspondência (bairro, cidade, estado, país e CEP): Programa de Pós-

Graduação em Eng. de Produção/CT-UFPB Jardim Universitário s/n - Castelo Branco - João

Pessoa/PB - Brasil - CEP. 58.051-900

Telefones para contato: (83) 32167124

e-mail: robertalss@globo.com

Nome Completo: Luiz Bueno da Silva

Filiação institucional: Universidade Federal da Paraíba - UFPB

Departamento: Programa de Pós-Graduação em Engenharia de Produção

Função ou cargo ocupado: Professor Associado / Coordenador

Endereço completo para correspondência (bairro, cidade, estado, país e CEP): Programa de Pós-

Graduação em Eng. de Produção/CT-UFPB Jardim Universitário s/n - Castelo Branco - João

Pessoa/PB - Brasil - CEP. 58.051-900 
Telefones para contato: (83) 32167124

e-mail: bueno@ct.ufpb.br

\section{Nome Completo: Maria de Lourdes Barreto Gomes}

Filiação institucional: Universidade Federal da Paraíba - UFPB

Departamento: Programa de Pós-Graduação em Engenharia de Produção

Função ou cargo ocupado: Professor Associado

Endereço completo para correspondência (bairro, cidade, estado, país e CEP): Programa de Pós-

Graduação em Eng. de Produção/CT-UFPB Jardim Universitário s/n - Castelo Branco - João

Pessoa/PB - Brasil - CEP. 58.051-900

Telefones para contato: (83) 32167124

e-mail: marilu@ct.ufpb.br

\section{Nome Completo: Valeska Lisandra de Menezes}

Filiação institucional: Universidade Federal da Paraíba - UFPB

Departamento: Programa de Pós-Graduação em Engenharia de Produção

Função ou cargo ocupado: Mestranda

Endereço completo para correspondência (bairro, cidade, estado, país e CEP): Programa de Pós-

Graduação em Eng. de Produção/CT-UFPB Jardim Universitário s/n - Castelo Branco - João

Pessoa/PB - Brasil - CEP. 58.051-900

Telefones para contato: (83) 32167124

e-mail: menezes_valeska@hotmail.com

Recebido em: 13/09/2011

Aceito em: 30/08/2012 